\title{
PENERAPAN TEKNIK ECONOMIC MOVEMENT GITAR PADA LAGU TANGO EN SKAI KARYA ROLAND DYENS
}

\author{
Achmad Nabila \\ Program Studi Pendidikan Sendratasik Fakultas Bahasa dan Seni Univesitas Negeri Surabaya \\ E-Mail : achmadnabila566@gmail.com
}

\begin{abstract}
Classical guitar has several positions when playing a reportoar. This is because the guitar has more than one tone with the same pitch. Tango En Skai has several positions and movement that are dificult, so that this study aims to describe the application of economic movement to tango En Skai works by Roland Dyens. This study discusses the economic movement of guitar in Tango En Skai. The approach used in this study is descriptive qualitative. Data collection is done by observations, documentation and interviews. Observations is done by playing, listening and analyzing the Tango En Skai score. Interviews were conducted with experts on the guitar namely Oegmundur Thor Johanneson, and Fernandez Setiahadi Chandra. Data analysis techniques used include three stages, there are data reduction, display data and conclutions or verification. The results showed that the application of economic movement has an effect on the played. Because classical guitar have quite difficult positions especially in modern works such as Tango En Skai. With economic movement, positions or technique whose movements are dificult on Tango En Skai can be done easily, both the right hand and the left hand. In Tango En Skai there are 16 economic movement. in the intro section there is one economic movement, period A there are 11 economic movement, period $\mathrm{B}$ there are 4 economic movement.
\end{abstract}

\section{Keyword : Economic Movement, Tango En Skai}

\begin{abstract}
Abstrak : Gitar klasik memiliki beberapa posisi ketika memainkan sebuah reportoar. Hal tersebut dikarenakan gitar memiliki lebih dari satu nada dengan pitch yang sama. Di dalam Tango En Skai terdapat beberapa posisi dan gerakan yang cukup sulit sehingga penelitian ini bertujuan untuk mendeskripsikan penerapan economic movement pada lagu Tango En Skai karya Roland Dyens. Penelitian ini membahas tentang gerakan yang ekonomis terhadap teknik permainan gitar yang ada pada Tango En Skai. Pendekatan yang digunakan dalam penelitian ini adalah kualitatif deskriptif. Pengumpulan data dilakukan dengan observasi, dokumentasi dan wawancara. Observasi dilakukan dengan cara memainkan, mendengarkan dan menganalisa score Tango En Skai. Wawancara dilakukan dengan ahli dalam gitar yaitu Oegmundur Thor Johanneson, dan Fernandez Setiahadi Chandra Teknik analisis data yang digunakan meliputi tiga tahap yaitu reduksi data, display data dan kesimpulan atau veifikasi. Hasil penelitian menunjukkan bahwa penerapan economic movement berpengaruh pada permainan, karena gitar klasik memiliki posisi-posisi yang cukup sulit apalagi pada karya-karya modern seperti Tango En Skai. Dengan economic movement, posisi-posisi atau teknik yang gerakannya cukup sulit pada Tango En Skai dapat dilakukan dengan mudah, baik itu jari tangan kanan maupun tangan kiri. Dalam Tango En Skai terdapat 16 economic movement, yaitu pada bagian intro, periode A dan periode B. Pada bagian intro terdapat 1 economic movement, Periode A terdapat 11 economic movement, dan Periode B terdapat 4 economic movement.
\end{abstract}

Kata kunci : Economic Movement, Tango En Skai

\section{PENDAHULUAN}

Gitar merupakan alat musik yang populer dan gitar begitu cepat berevolusi dari masa ke masa yang menjadikan gitar mempunyai banyak jenis, salah satunya adalah gitar klasik. Gitar klasik memiliki tiga bagian utama seperti pada gitar jenis lainya yaitu head stock, neck dan body. Pada bagian head stock terdapat mesin penala dawai yaitu tuning pack. Dawai gitar yang berjumlah enam utas terbuat dari nylon yang dipasang pada senar satu sampai 3 dan benang yang dililit dengan kawat logam yang dipasang pada senar empat sampai 5, penggunaan senar tersebut yang menjadikan gitar klasik berbeda dengan jenis gitar lainnya.

Permainan gitar klasik tidak bisa lepas dari teks atau partitur. Pada dasarnya partitur merupakan suatu media yang berisi tanda-tanda atau yang biasa disebut dengan notasi musik. Dengan teks atau partitur yang telah ditulis oleh komponis para pemain gitar klasik dapat menyampaikan maksud yang terkandung dalam 
karya tersebut lewat permainan gitarnya. Dalam hal ini, orang yang akan memainkan suatu karya harus bisa membaca dalam teks musik atau partitur yang telah ditulis oleh komponis dan perkembangan penulisan teks musik atau partitur begitu berbeda-beda dari masa ke masa. Perbedaan tersebut terlihat dalam penulisan teks musik atau partitur pada beberapa periode dari zaman renaisance, baroque, classic, romantic, musik abad 20 yang biasa kita kenal sebagai musik modern dan sampai sekarang pada musik abad 21 .

Masing-masing zaman mempunyai karakter yang berbeda dalam hal karya, teknik atau penulisan teks musiknya. Terutama pada abad 20 dan 21 dimana banyak karya dari para komponis besar untuk instrument gitar klasik seperti Joaquin Rodrigo, Britten, Carlo Dominiconi, Francis Kleyjans, Roland Dyens dan Leo Brouwer yang memberikan banyak perubahan besar dalam ruang permainan gitar klasik lewat karya-karyanya yang mempunyai karakter yang khas. Roland Dyens merupakan komposer yg memiliki gaya dan karakter yang khas pada setiap karya- karyanya.

Roland Dyens lahir pada 19 oktober 1955 di Perancis. Beliau adalah seorang composer, arranger sekaligus player gitar klasik. Dyens belajar gitar ketika umur sembilan tahun. Empat tahun kemudian ia belajar gitar dengan seorang maestro yaitu Alberto Ponce. Pada tahun 1976 Dyens mendapatkan penghargaan pada sebuah acara de Concert de I'Ecole Normale de Musique de Paris. Dyens juga belajar komposisi dengan musisi besar yakni Desire Dondeyne. Pada usia 25 tahun, ia menjadi pemenang dari Yehudi Menuhin Foundation. Delapan tahun kemudian, ia diakui sebagai salah satu Best Living Guitarist di semua majalah Gitar Perancis. Pada 21 Januari 2010, Roland Dyens mendapat hak istimewa untuk menjadi satusatunya gitaris klasik yang diundang untuk berpartisipasi untuk sebuah penghormatan acara Django Reinhardt, dalam konser yang akan diberikan pada legendaris Theatre du Châtelet di Paris. Pada bulan Juli 2011, Dyens mengadakan resital gitar di Cordoba dan menerima penghargaan tertinggi dari Spanyol Press.

Sebagai pemain, Dyens dikenal karena improvisasinya. Kadang-kadang dia membuka konsernya dengan karya improvisasi, dan dia mungkin mengimprovisasi program itu sendiri, tanpa merencanakan atau mengumumkan sebelumnya apa yang akan dia mainkan. Dia mengatakan bahwa seorang jurnalis pernah mengatakan kepadanya bahwa dia memiliki tangan seorang musisi klasik tetapi pikiran seorang musisi jazz. Dia memainkan suite Bach dan dia bermain dengan musisi jazz di Arvika Festival di Swedia. Sebuah band heavy metal melakukan versi gerakan ketiga Libra Sonatine-nya. Dyens merilis beberapa volume aransemen yang tidak hanya mencakup musik klasik tetapi juga musik Brasil, standar jazz oleh Thelonious Monk, pop Prancis Edith Piaf, dan jazz Gipsi Django Reinhardt. Salah satu karya paling terkenal dari Roland Dyens adalah Tango En Skai. karya ini merupakan karya pendek namun memiliki teknik yang cukup sulit untuk dimainkan.

Tango en Skaï Diterbitkan pada tahun 1985 oleh Henry Lemoine, Tango en Skaïadalah salah satu improvisasi Dyens hingga disarankan untuk benar-benar menulisnya. Judul diterjemahkan secara harfiah sebagai Tango dan Skai dalam bahasa Perancis mempunyai arti kulit imitasi yang lebih jelek dari plastik. Karya ini dimainkan dengan penuh humor, yang berarti dalam musik dimainkan dengan dinamika yang sangat kontras dan penggunaan rubato yang sesedikit mungkin.

Karya komposisi ini dimainkan dengan tonalitas A minor, bersukat 4/4 dan dimainkan dengan tempo moderato. Komposisi ini mempunyai bentuk free form, harmonisasi bertekstur polifoni, dinamika sangat kontras, dan akord sebagian besar didominasi oleh diminished seventh. Ini adalah cara Dyens yang sangat unik untuk menandakan bahwa karya ini adalah karikatur dari tango atau mungkin 
Achmad Nabila

PENERAPAN TEKNIK ECONOMIC MOVEMENT GITAR PADA LAGU TANGO EN SKAI KARYA ROLAND DYENS

replika yang cerdas. Nada ringan yang dimunculkan pada bagian awal terdapat ekspresi Un rien canaille pada notasi (perkiraan terjemahan: "bajingan tidak berharga") untuk menginstruksikan pemain untuk menjadi sedikit vulgar atau kasar dengan proses. Selain mengeksplore teknik gitar karya ini juga menggunakan polyritmik namun tetap memunculkan irama tango.

Kelincahan nada-nada yang digunakan, serta banyaknya teknik permainan gitar klasik yang digunakan dalam Tango En Skai menyita perhatian siapapun yang memainkannya. Akan tetapi, banyak pemain gitar klasik yang masih kesulitan untuk memainkan lagu ini karena kurangnya skill yang dimiliki, serta kurangnya pengetahuan mengenai teknik dalam memainkan gitar klasik. Dalam memainkan reportoar gitar klasik perlu diketahui dan dilatih teknik dasar dalam permainan gitar klasik karena gitar klasik merupakan gitar akustik yang tidak memiliki bantuan pengeras suara (pre-amp) atau hanya mengandalkan kualitas dari gitar itu sendiri. Sehingga untuk memproduksi suara yang bagus sangat ditentukan oleh kemampuan orang yang memainkannya (gitaris).

Dalam gitar terdapat beberapa posisi ketika memainkan sebuah reportoar. Hal tersebut dikarenakan gitar memiliki lebih dari satu nada yang berbunyi sama atau dengan pitch yang sama. Sebagai contoh, nada $\mathrm{C} 1$ atau $\mathrm{C}$ middle di dalam instrumen gitar terdapat dua $\mathrm{C}$ middle yaitu pada fret 2 senar 5 dan fret 8 senar 6. Hal tersebut yang membuat gitar memiliki banyak alternatif dalam pemilihan posisi. Pemilihan posisi juga berpengaruh terhadap nada yang dibunyikan. Oleh sebab itu maka di dalam pemilihan posisi harus memperhatikan gerakan atau perpindahan yang ekonomis dan efisien (economic movement)

Mengacu pada penjelasan tersebut, serta kajian mengenai pentingnya suatu pemahaman mengenai teknik permainan gitar klasik bagi masyarakat di lingkungan musik, sehingga perlu diketahui tahapan dan cara melatih teknik pada gitar klasik. Dalam penelitian ini dilakukan pengkajian yang lebih lanjut dan mendalam, khususnya menyangkut cara melatih teknik permainan gitar klasik yang digunakan, serta etude untuk menunjang teknik permainan dari Tango En Skai karya Roland Dyens. Hal tersebut yang membuat menarik untuk diteliti ditinjau dari teknik permainan dan faktor-faktor pendukung teknik permainan yang digunakan dalam lagu Tango En Skai karya Roland Dyens.

\section{METODE}

Metode penelitian yang digunakan adalah metode penelitian kualitatif deskriptif. Hal tersebut dikarenakan data yang terkumpul berbentuk kata-kata atau gambar dan bukan berupa angka-angka, seperti yang diungkapkan Bagdan dan Biklen (dalam Sugiyono, 2011: 13), bahwa "penelitian kualitatif lebih bersifat deskriptif, data yang terkumpul berbentuk katakata atau gambar sehingga tidak menekankan pada angka". Dalam penelitian kualitatif, data berasal dari dokumentasi penelitian, pengawasan, evaluasi, pengamatan pendahuluan dan pernyataan dari narasumbernarasumber yang dipercaya. Peneliti berusaha mendeskripsikan metode latihan dan penerapan teknik economic movement pada lagu Tango En Skai karya Roland Dyens, sehingga digunakan penelitian kualitatif deskriptif.

Sumber data primer merupakan sumber data yang langsung memberikan data kepada pengumpul data (sugiyono 2016: 225). Dalam penelitian ini data primer berupa score atau partitur Tango En Skai karya Roland Dyens yang diterbitkan oleh Henry Lemoine dan Sumber data sekunder dalam penilitian ini berupa dokumentasi dalam bentuk rekaman video pertunjukan saat memainkan Tango En Skai.

Teknik pengumpulan data yang digunakan dalam penelitian ini yaitu Observasi, wawancara dan dokumentasi. Peneliti melakukan observasi dengan cara masterclass 
langsung dari para ahli, baik sebagai peserta aktif maupun pasif. Peneliti membaca dan memainkan teks (partitur) Tango En Skai karya Roland Dyens kemudian menganalisa partitur. Wawancara ditujukan kepada para ahli dibidang teknik permainan gitar diantaranya yaitu Ögmundur Pór Jóhannesson dan Fernandez Setiahadi Candra. Dokumentasi disini berupa dokumentasi tertulis yaitu partitur, artikel, dan audio visual mengenai Tango En Skai karya Roland Dyens.

Dalam melakukan analisis data, peneliti menggunakan tiga komponen yaitu reduksi data, penyajian data dan penyimpulan. Menurut Miles dalam Bungin (2007: 296) menjelaskan proses pegumpulan analisis data melalui tiga tahapan model yaitu reduksi data, penyajian data dan verifikasi.

Dalam tahap reduksi data peneliti memusatkan perhatian pada data lapangan yang telah terkumpul. Tahapan selanjutnya dalam reduksi data adalah proses pemilihan, pemusatan, penyederhanaan data penelitian. Data tersebut berupa partitur, video, dan hasil wawancara. Peneliti perlu melakukan pemilihan data-data yang dianggap pokok sehingga data yang diperoleh dapat mendukung penelitian ini (Bungin, 2007: 297).

Pada tahap penyajian data, peneliti melakukan penyajian informasi melalui teks naratif. Seperti yang telah dijelaskan oleh Bungan dalam penelitian ini, proses menyajikan data dilakukan dengan teks yang bersifat naratif (Bungin, 2007: 297). Teks tersebut memuat seluruh data yang berupa deskripsi teknik permainan Gitar Tango En Skai.

Data yang telah tersaji secara sistematis dan terperinci, selanjutnya peneliti melakukan proses penarikan kesimpulan yang semula belum jelas, melalui data-data yang telah bertambah maka dapat ditarik kesimpulan yang jelas dengan menganalisis secara kualitatif.

\section{HASIL DAN PEMBAHASAN}

Tango en Skai merupakan komposisi modern dimana banyak posisi-posisi dengan teknik yang cukup sulit. Maka untuk memainkan dengan maksimal, perlu eksperimen mencoba beberapa posisi, dan dibawah ini merupakan posisi terbaik dalam memainkan Tango En Skai karya Roland Dyens.

\section{Bagian Intro}

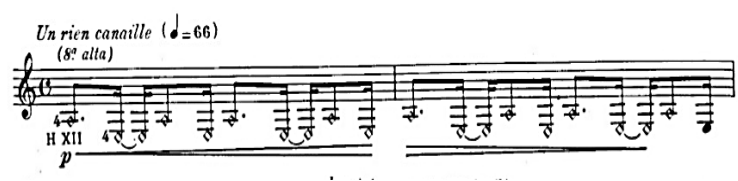

Gambar 1 : economic movement Tango En

Skai birama 1-2.

(sumber: 10.000 scores)

Pada bagian intro diatas dimainkan dengan teknik harmonic pada fret ke 12 nada $\mathrm{A}$ pada senar 5 dan nada E pada senar 6. Teknik harmonic dilakukan dengan menyentuh senar tapi tidak sampai memberi tekanan dengan kelingking jari kiri. Penggunaan jari 4 atau kelingking bertujuan untuk mempersiapkan jari 1,2 dan 3 menekan nada berikutnya. Sedangkan jari tangan kanan memetik dengan ibu jari menggunakan petikan appoyando (rest stroke) karena melodi tersebut terletak pada bass.

\section{Periode A}
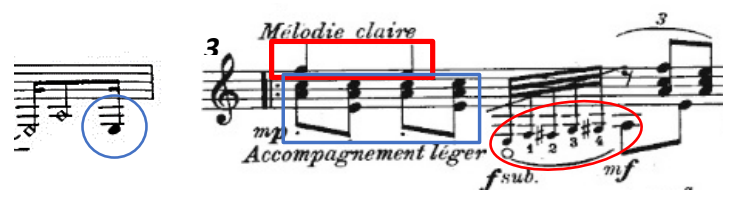

Gambar 2 : economic movement Tango En

Skai birama 2 dan 3.

(sumber: 10.000 scores)

Sebelum memasuki birama ke 3, nada terakhir pada birama kedua dibunyikan normal atau arco yang terletak pada senar 6 dengan posisi lepas (open string). Ketika membunyikan nada tersebut, keempat jari mempersiapkan 
Achmad Nabila

PENERAPAN TEKNIK ECONOMIC MOVEMENT GITAR PADA LAGU TANGO EN SKAI KARYA ROLAND

DYENS

untuk nada berikutnya pada birama 3 pada posisi 1 (fret 1). Ketukan pertama jari 1 posisi barre pada nada $\mathrm{F}$ dan $\mathrm{C}$, sedangkan nada A ditekan jari 3, nada E ditekan jari 2. Untuk tangan kanan memetik menggunakan jari $i, m$ dan $a$. bergantian setelah senar 1,2,3 kemudian not berikutnya senar 2,3,4 dengan teknik staccato pada senar 2,3,4 nada E,A dan C pada kotak warna biru. Sedangkan kotak warna merah pada nada $\mathrm{F}$ dan $\mathrm{E}$ di biarkan sustain selama panjang not karena kotak merah merupakan melodi.

Pada lingkaran merah terdapat teknik slide dimana empat nada dibunyikan hanya dengan satu petikan, namun slide kali ini menggunakan jari kiri 1,2,3 dan 4 dengan memukul senar (pulling). Nada E adalah open string kemudian nada selanjutnya dipukul dengan jari tangan kiri. Nada $F$ jari 1, nada F\# jari 2, nada $G$ jari 3, dan nada G\# pada jari 4 . Sedangkan nada A dipetik menggunakan ibu jari pada senar 5 (open string).

Untuk dapat membunyikan dengan maksimal, bisa dilatih dengan temr- yang pelan terlebih dahulu dan dengan suara yang jelas. Ketika tempo pelan sudah jelas dan harga not terbunyi rata, naikkan tempo secara bertahap hingga mencapai tempo asli.

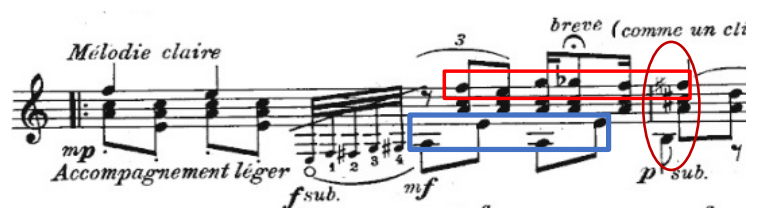

Gambar 3 : economic movement Tango

En Skai birama 3-4.

(sumber: 10.000 scores)

Pada birama 3-4 mulai ada polyritmis antara bass dan iringan melodi. Kotak merah adalah melodi utama dengan skala chromatic dimana nada nya bercampur satu ritmis dengan iringan. Melodi tersebut harus terdengar dengan jelas ketika dipetik menggunakan jari $a$ atau kelingking tangan kanan. Sehingga harus mengatur tekanan yg diberikan antara jari $p, i$, $m$ dan $a$. namun jari $a$ harus yang paling menonjol pada bagian ini karena merupakan melodi utama. Posisi pada melodi tersebut tetap pada posisi I dimana jari 1 barre dengan nada $\mathrm{C}$ dan F, nada E menggunakan open string, nada $\mathrm{G}$ dan $\mathrm{Gb}$ menggunakan jari 4.

Pada lingkaran merah tetap menggunakan posisi I dimana nada B pada jari 2 senar 5, nada A pada jari 3 senar 3, nada C\# pada jari 4 senar 2 dan nada $F$ pada jari 1 senar 1. Untuk membunyikan akord ini cukup sulit karena nada sebelumnya juga akord, jadi memerlukan perpindahan yang cepat dan posisi yang presisi ke akord yang akan dibunyikan. Tetapi masalah tersebut bisa diatasi dengan latihan menggunakan tempo yang lambat terlebih dahulu sampai bunyi terdengar jelas kemudian dapat menaikkan tempo secara bertahap sampai ke aslinya.

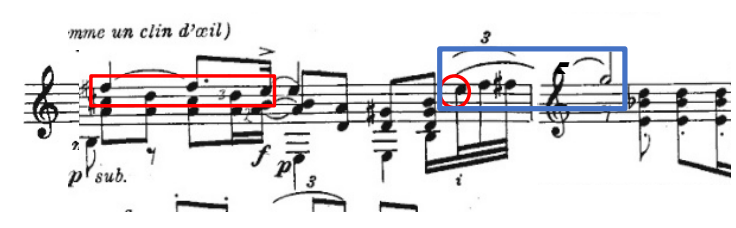

Gambar 4 : economic movement Tango

En Skai birama 4-5.

(sumber: 10.000 scores)

Birama 4 nada $\mathrm{F}$ dipertahankan sustain dengan jari 1 karena ada legato. Disini yang bergerak adalah jari 4 . Jari 4 bergeser dari nada C\# ke D. Dan ketika membunyikan nada B, jari 4 dilepas karena nada tersebut terletak pada posisi open string senar 2.

Ketika membunyikan E pada lingkaran merah, segera lepaskan jari yang menekan nada sebelumnya dan segera pukulkan jari 1 ke nada $\mathrm{F}$ pada fret 1 senar 1 . Kemudian nada $\mathrm{F}$ pada jari 2 dan yang terakhir nada $G$ birama 5 menggunakan jari 4. Nada-nada tersebut merupakan satu rangkaian yang tidak boleh putus karena terdapat legato dari akhir birama 4 menuju birama 5, dibunyikan dengan memetik appoyando pada nada $\mathrm{E}$ kemudian pulling menggunakan jari 1,2 dan 4. Pada birama 5, jari 4 tetap menahan selama harga not yaitu dua ketuk dan nada selanjutnya ditekan jari 3 pada nada $\mathrm{D}$, jari 2 pada nada $\mathrm{Bb}$ dan jari 1 pada nada 
E, dibunyikan dengan teknik staccato oleh tangan kanan dan pada posisi sul ponticello (dekat bridge).

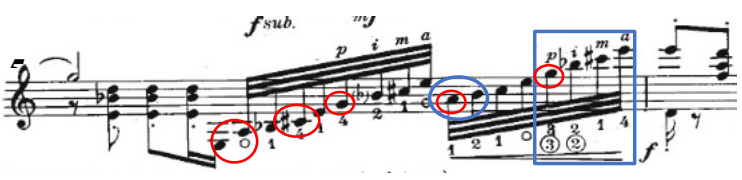

Gambar 5 : economic movement Tango En Skai birama 5.

(sumber: 10.000 scores)

Dalam Birama 5 terdapat not $1 / 32$ dengan nada dari diminish scale yang memerlukan speed untuk memainkan. Penggunaan ibu jari pada tangan kanan sangat penting untuk bisa mencapai kecepatan yang tinggi. Petikan yang digunakan adalah free stroke (tirando) karena pergerakan jari tangan kanan dituntut untuk cepat. Nada E dan A pada lingkaran merah dibunyikan menggunakan jari $p$ dan nada berikutnya menggunakan jari $i$. Kemudian nada $\mathrm{Bb}, \mathrm{C} \#$ dan E pada oktaf yang tinggi, menggunakan jari $i, m$ dan $a$.

Pada lingkaran biru, nada $\mathrm{A}$ dan $\mathrm{Bb}$ dibunyikan dengan satu petikan pada nada $\mathrm{A}$ dan penggunaan pulling pada nada $\mathrm{Bb}$ dengan jari 2. Pada kotak berwarna biru mulai berpindah posisi, yang sebelumnya berada di posisi II kemudian pindah di posisi IX. Tangan kiri mendapat jeda yang cukup untuk melakukan perpindahan posisi yang cukup jauh yaitu ketika membunyikan nada $\mathrm{E}$, karena nada tersebut terletak pada open string. Nada G terletak di senar 3 dengan jari 3 , nada $\mathrm{Bb}$ terletak di senar 2 jari 2 , nada $\mathrm{C \#}$ terletak di senar 1 jari 1 dan nada $E$ terletak di senar 1 dengan jari 4.

Ketika membunyikan nada E dan D pada birama 6, jari 1 siap-siap untuk melakukan barre pada posisi $\mathrm{X}$ dan nada yang dibunyikan adalah F, A dan D. Kemudian nada D pada bass, sustainnya dihentikan menggunakan ibu jari karena terdapat tanda rest atau istirahat setelah nada tersebut.

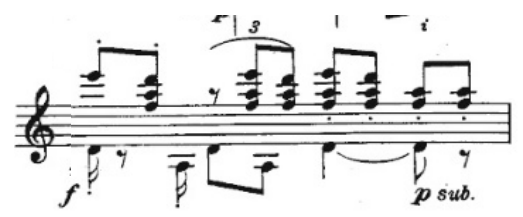

Gambar 6 : economic movement Tango En Skai birama 6. (sumber: 10.000 scores)

Birama 6 dimainkan dengan suara yang keras karena terdapat tanda $f$ pada score. Nada bass A dan D dipetik menggunakan jari $p$ pada open string 5 dan 4 . Kemudian pada ketukan ketiga dimainkan dengan staccato menggunakan jari $i, m$ dan $a$. pada ketukan keempat birama 6 , memetik dengan jari $i$ dan $m$ yang mengarah pada posisi sul tasto untuk mendapatkan bunyi pelan dan lembut.

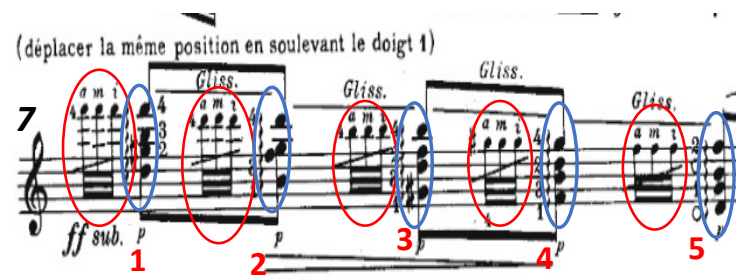

Gambar 7 : economic movement Tango En Skai birama 7. (sumber: 10.000 scores)

Birama 7 terdapat beberapa teknik yang cukup sulit untuk dimainkan, diantaranya tremolo, glissando dan rasgueado. Ketiga teknik tersebut dimainkan dengan tempo yang cepat dan posisi yang berpindah-pindah. Pada lingkaran merah merupakan teknik tremolo yang dimainkan di senar 1 menggunakan jari $i, m$ dan $a$, yang ditekan dengan jari 4 . Kemudian dilanjutkan dengan teknik rasgueado menggunakan jari $p$ mulai dari senar 4 sampai senar 1. Pada tremolo dan rasgueado pertama terdapat pada posisi XII. Nada F pada jari 4, nada B pada jari 3 senar 2, nada G\# pada jari 3 senar 3 dan nada D pada jari 1 senar 4 . Pada tremolo dan rasgueado kedua terdapat pada posisi IX dengan nada D pada jari 4 senar 1, nada G\# pada jari 2 senar 2, nada $F$ pada jari 3 senar 3, dan nada B pada jari 1 senar 4. Pada tremolo dan rasgueado ketiga terdapat pada posisi VI dengan nada B pada jari 4 senar 1, nada $F$ jari 2 senar 2, nada D jari 3 senar 3,nada 
Achmad Nabila

PENERAPAN TEKNIK ECONOMIC MOVEMENT GITAR PADA LAGU TANGO EN SKAI KARYA ROLAND DYENS

G\# jari 1 senar 4. Pada tremolo dan rasgueado keempat terdapat pada posisi III dengan nada $\mathrm{G} \#$ pada jari 4 senar 1 , nada $\mathrm{D}$ jari 2 senar 2, nada B jari 3 senar 3, dan nada F jari 1 senar 4. Pada tremolo dan rasgueado kelima terdapat pada posisi I dengan nada $\mathrm{F}$ pada jari 4 senar 1, nada B open senar 2, nada G\# jari 3 senar 3, dan nada D open senar 4. Ketika memainkan teknik rasgueado, segera menarik atau menyeret jari-jari tangan kiri untuk melakukan teknik slide ke posisi berikutnya kemudian kembali lagi ke tremolo. Hal ini dapat dilatih dengan tempo lambat dilakukan dengan konstan dan stabil sehingga setiap not terdengar jelas. Setelah dilakukan terusmenerus sampai terasa nyaman di jari, mulai lah untuk menambah tempo secara bertahap dan selalu perhatikan jari tangan kanan dan tangan kiri agar berjalan sesuai teknik yang benar. Berlatih dengan tempo lambat bertujuan agar setiap jari terbiasa dengan gerakan tersebut dan untuk memperoleh kestabilan tempo terhadap not yang dimainkan.

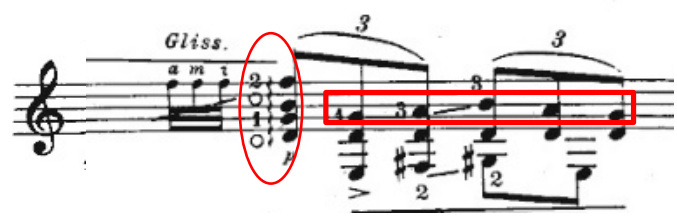

Gambar 8 : economic movement Tango En

Skai birama 7.

(sumber: 10.000 scores)

Gambar 8 menunjukkan karakter tango pada bass yang besar dan tegas. Setelah memainkan arpeggio, jari 3 yang menekan nada G\# tetap menempel pada senar 3 karena nada yang di dalam kotak merah terdapat di senar nomor 3. Dan pada bass, memakai jari 2. Nada bass E menggunakan open string. Untuk jari tangan kanan menggunakan jari $p$ pada bass, dan jari $i, m$ pada nada dalam kotak merah.

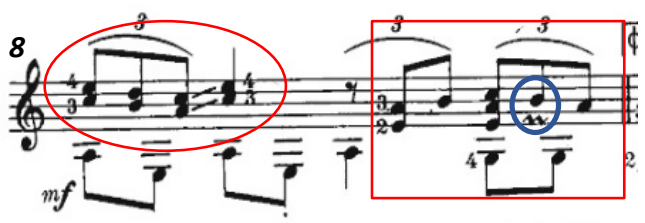

Gambar 9 : economic movement Tango En

Skai birama 8.

(sumber: 10.000 scores)

Birama 8 awal, dimainkan dengan lembut dengan cara memetik pada posisi normal kemudian bergeser kearah fingerboard atau bergeser ke arah sul tasto. Nada C menggunakan jari 3 senar 3 , nada $E$ menggunakan jari 4 senar 2. Berikutnya nada $B$ menggunakan jari 2 senar 3 , nada D menggunakan jari 1 senar 2, kemudian jari 1 dan 2 digeser ke belakang ke nada $\mathrm{A}$ dan $\mathrm{C}$ lalu diseret ke arah nada $\mathrm{C}$ dan $\mathrm{E}$ karena ada Teknik glissando. Ketika membunyikan nada $\mathrm{C}$ dan $\mathrm{E}$ kembali lagi menggunakan jari 3 dan 4 .

Pada kotak merah, dimainkan dengan cukup tegas pada posisi I. Nada E menggunakan jari 2, nada A menggunakan jari 3. Nada B menggunakan open senar 2. Nada C menggunakan jari 1. Kemudian teknik trill menggunakan jari 1. Adapun nada yang di trill adalah B ke C. Untuk melakukan teknik trill kali ini cukup sulit karena selain posisinya di bawah, jari 2, 3 dan 4 berada diatas jari 1 sehingga kekuatan jari 1 untuk membunyikan trill sangat diandalkan supaya dapat membunyikan dengan jelas. Cara melatihnya adalah dengan memasang posisi seperti pada score dimana jari 2, 3, dan 4 tetap menempel dan menekan senar 4, 5 dan 6 kemudian jari 1 melakukan trill dengan tempo pelan tetapi nada berbunyi dengan jelas dan dilakukan berulangulang hingga jari 1 kuat membunyikan trill tersebut dengan jelas.

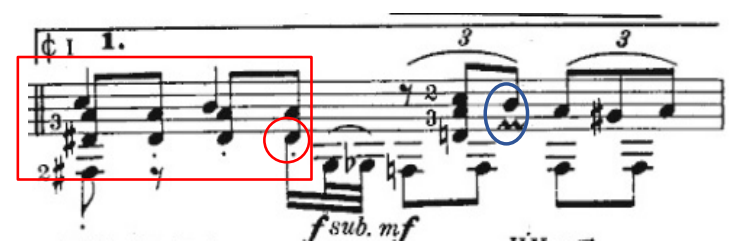

Gambar 10 : economic movement Tango En Skai birama 9 . (sumber: 10.000 scores 
Ketukan pertama terdapat di posisi I, dengan barre jari 1 pada nada D\# dan C. Nada bass F\# menggunakan jari 2, nada A menggunakan jari 3. Kemudian jari melepaskan barre ketika membunyikan nada B, tetapi ujung jari tetap menekan nada D\#. Untuk jari tangan kanan pada nada D\# dan A menggunakan jari $i$ dan $m$ dengan melakukan teknik staccato. Nada $\mathrm{C}$ dan B sebagai melodi menggunakan jari $a$. setelah membunyikan nada D\# pada lingkaran merah, jari $i$ harus tetap menempel pada senar 4 untuk menghentikan sustain dan mencegah terbunyi nya nada D karena jari 2 melakukan perpindahan menuju senar 6 pada nada bass. Pelepasan tersebut sangat rawan membunyikan nada D ketika tidak dihentikan oleh jari $i$ tangan kanan.

Selanjutnya teknik slur pada bass dilakukan oleh jari 3 ke jari 2. Nada G menggunakan jari 3, nada Gb menggunakan jari 2 dan nada $\mathrm{F}$ menggunakan jari 1. Teknik trill selanjutnya dilakukan oleh jari 2 dengan nada B di trill ke nada C. Sama seperti sebelumnya, trill ini sulit dilakukan karena jari yang lain berada di senar atasnya.

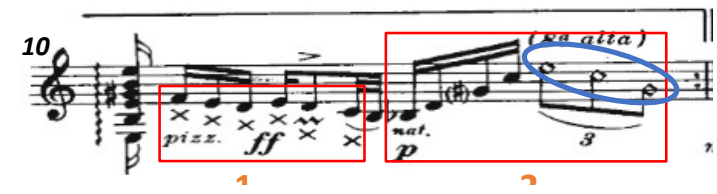

Gambar 11 : economic movement Tango En Skai birama 10.

(sumber: 10.000 scores)

Pada birama 10 terdapat beberapa teknik, diantaranya arpeggio, pizzicato, trill dan harmonic. Awal birama 10 teknik arpeggio menggunakan jari $p$ dengan akord $\mathrm{E}$ major posisi I. Selanjutnya teknik pizzicato pada kotak merah menggunakan jari 3 dan 2 . Pizzicato ini dipetik oleh jari $p$, dengan tumit tangan kanan menyentuh senar di dekat bridge. Trill dilakukan oleh jari 2 dari nada D ke E.

Kotak merah kedua dipetik kembali normal, nada $\mathrm{Bb}$ ditekan dengan jari 1, nada $\mathrm{D}$ open string nada $\mathrm{G} \#$ menggunakan jari 2 dan nada $\mathrm{C}$ menggunakan jari 3. Untuk tangan kanan, nada $\mathrm{Bb}$ dan $\mathrm{D}$ menggunakan jari $p$, nada $\mathrm{G} \#$ menggunakan jari $i$, nada $\mathrm{C}$ menggunakan jari $m$. Ketika memetik nadanada tersebut, tangan kanan sambil menggeser ke arah fingerboard fret 12 dan jari $a$ menempel pada senar 1 karena akan melakukan teknik harmonic. Teknik harmonic ini dilakukan dengan menyentuh fret ke-12 dari nada yg akan dibunyikan, fret ke-12 disentuh dengan ujung jari $i$ tangan kanan dan dipetik dengan jari $a$. jadi jari $a$ memetik bersamaan dengan ujung jari $i$ menyentuh senar.

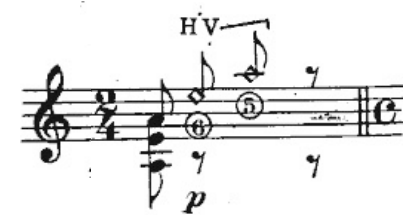

Gambar 12 : economic movement Tango En

Skai birama 12.

(sumber: 10.000 scores)

Pada birama ini terletak di dua posisi. posisi pertama yaitu di posisi I dengan nada $\mathrm{E}$ menggunakan jari 2, nada A menggunakan jari 3. Posisi kedua berada pada posisi V menggunakan teknik harmonic nada E pada senar 6 dan nada A pada senar 5 .

\section{Periode B}

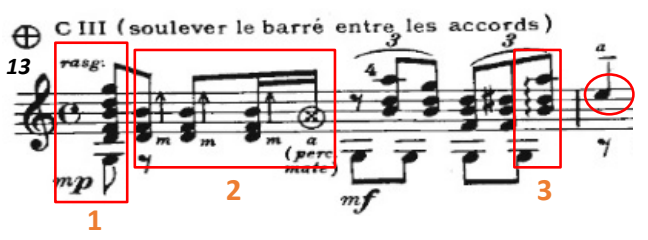

Gambar 13 : economic movement Tango En

Skai birama 13.

(sumber: 10.000 scores)

Birama ke-13 terletak di posisi III dengan tangan kiri melakukan barre, seperti pada score tertulis (soulever le barre entre les accords). Pada awal birama ke-12, tangan kiri melakukan barre pada akord $\mathrm{G}$ maj7 dengan teknik rasgueado menggunakan tiga jari untuk membunyikannya yaitu dengan jari $i, m$, dan $a$. kemudian nada berikutnya strumming 
menggunakan jari $m$ dari senar 4 sampai senar 2. Setelah melakukan strumming, tanda $\mathrm{x}$ dimainkan dengan memukul soundboard tepat dibawah soundhole menggunakan jari $m$, karena pergerakan jari tersebut sangat efektif setelah strumming ke arah bawah kemudian ditarik dan dipukulkan ke arah soundboard.

Pada kotak ketiga,terdapat teknik arpeggio dengan nada $\mathrm{B}$ dipetik menggunakan jari $i$, nada $\mathrm{D}$ menggunakan jari $m$, nada $\mathrm{A}$ menggunakan jari $a$. kemudian untuk membunyikan nada $\mathrm{E}$ pada lingkaran merah, menggunakan jari $m$ dan nada tersebut terletak di open senar 1 .

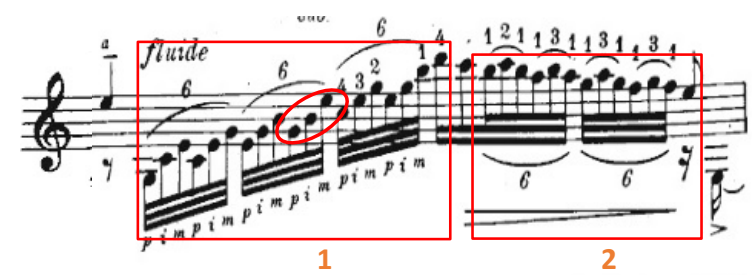

Gambar 14 : economic movement Tango En Skai birama 14.

(sumber: 10.000 scores)

Kecepatan jari tangan kanan sangat diperlukan untuk dapat memainkan bagian ini. Pada kotak pertama lebih fokus pada jari-jari tangan kanan karena jari tangan kiri hanya sedikit melakukan gerakan. Jari tangan kanan melakukan petikan secara berurutan dari senar 6 sampai senar 1 menggunakan jari $p$, $i$, dan $m$. Jari tangan kiri melakukan perpindahan posisi dari posisi II menuju posisi VII. Perpindahan tersebut dapat dilakukan ketika jari kanan memetik nada yg ada pada lingkaran merah. Nada-nada tersebut berada pada posisi open string.

Selain kecepatan jari tangan kanan, pada kotak kedua lebih fokus kepada jari-jari tangan kiri. Kecepatan, kekuatan dan akurasi sangat penting pada bagian ini agar dapat membunyikan secara maksimal. Jari tangan kiri melakukan slur naik dan slur turun dalam satu petikan kemudian pindah ke posisi selanjutnya. Posisi pertama yaitu di posisi VII, kedua pada posisi V, ketiga pada posisi III, dan keempat pada posisi I.
Untuk dapat memainkan speed pada bagian ini, tentu saja dilatih dengan tempo lambat terlebih dahulu untuk membiasakan jari terhadap gerakan tersebut dan memperoleh bunyi yang jelas dan rata. Hal ini harus dilakukan secara konsisten dan fokus supaya mendapat hasil yang optimal. Setelah jari terasa nyaman dan dapat memainkan dengan bersih, tempo bisa dinaikkan secara bertahap sampai ke tempo asli.

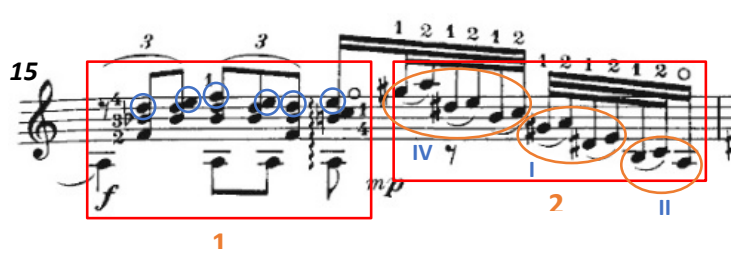

Gambar 15 : economic movement Tango En Skai birama 15. (sumber: 10.000 scores)

Kotak merah pertama terletak pada posisi I dengan nada $\mathrm{F}$ ditekan oleh jari 2, nada $\mathrm{Bb}$ ditekan jari 3, nada D ditekan jari 4 dan nada F ditekan jari 1. Melodi tetap harus terlihat jelas meski dipetik bersamaan dengan iringan, pemberian power pada melodi harus lebih kuat daripada iringan. Jari kanan $a$, harus lebih dominan dalam memetik melodi dalam lingkaran biru diatas. Selanjutnya terdapat teknik arpeggio yang dipetik menggunakan jari $p$ pada nada $\mathrm{A}$, jari $i$ pada nada $\mathrm{B}$, jari $m$ pada nada $\mathrm{C}$ dan jari $a$ pada nada $\mathrm{E}$.

Pada kotak merah kedua terdapat teknik slur naik yang dilakukan oleh jari 1 dan 2 terletak di posisi IV, I dan II. Karena posisi senar yang berpindah dan memerlukan kecepatan, maka petikan jari kanan harus diperhatikan. Jari tangan kanan harus bergantian antara $i$ dan $m$ untuk menghidari terselip. 


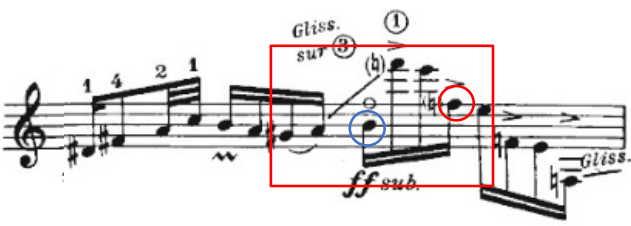

Gambar 16 : economic movement Tango En Skai birama 16.

Pada birama ini terdapat perpindahan posisi yang cukup jauh dari posisi I menuju posisi XII kemudian kembali lagi ke posisi I. Hal tersebut dapat dilakukan dengan mudah jika menggunakan teknik yang baik. Untuk bisa melakukan perpindahan dari posisi I ke posisi XII, terdapat satu kesempatan yang cukup untuk melakukan pergerakan yaitu ketika nada B (open string) dibunyikan, jari-jari tangan kiri segera melepaskan senar dan bergerak menuju posisi XII. Kemudian pada posisi XII, nada F ditekan oleh jari 4, nada E ditekan oleh jari 3. Jari 1 bersiap-untuk menuju posisi I untuk menekan nada $\mathrm{F}$ pada lingkaran merah

\section{PENUTUP}

Tango En Skai merupakan karya gaya modern yang diciptakan pada tahun 1985. Ritme cenderung lebih bebas dan tidak teratur, sering terjadi perubahan tanda sukat pada suatu karya komposisi yang mengakibatkan tempo dalam suatu lagu sering berubah-ubah. Ciri musik tango sendiri lebih memiliki aksen terutama dalam bass/root nada yang khas dari setiap sinkopasinya (syncop). Sering terjadi peralihan dinamika yang sangat kontras, seperti contoh munculnya dinamika $p$ menjadi sub atau sebaliknya. Pada Tango En Skai terdapat pada birama 6, 7, 10, 21 dan 22. Dalam Tango En Skai terdapat 16 economic movement, yaitu pada bagian intro, periode A dan periode B. Pada bagian intro terdapat 1 economic movement, Periode A terdapat 11 economic movement, dan Periode B terdapat 4 economic movement.

\section{DAFTAR PUSTAKA}

Andajani, Karina. 2014. Apa itu Musik?. Tangerang. CV. Marjin Kiri.

Banoe, Pono. 2003. Kamus Musik. Yogyakarta: Kanisius.

John, Rink. 1995. The Practice of Performance. London: Cambridge University Press.

Kristianto, J. 2007. Gitarpedia. Jakarta: PT Gramedia Pustaka Utama.

Moleong, J. L. 2007. Metodologi Penelitian Kualitatif, edisi revisi. Bandung: P.T. Remaja Rosdakarya.

Prier, K.E.1993. Sejarah Musik Jilid 2. Yogyakarta: Pusat MusikLiturgi.

Shearer, A. 1990. Learning The Classic Guitar Part One. U.S.A:Melbay Publications. 1990. Learning The Classic Guitar Part Two. U.S.A: Melbay Publications. 1991. Learning The Classic Guitar Part Three. U.S.A: Melbay Publications.

Sugiyono. 2006. Metode Penelitian Pendidikan (Kuantitatif, Kualitatif,dan $R \& D$ ). Bandung: C.V. Alfabeta.

Tenant, Ascott. 1995. Pumping Nylon, the classical guitarist's technique handbook. U.S.A: Alfred Publishing.

Thahir, Iqbal. 2003. Metode Gitar Klasik Modern Jilid 1. Jakarta: P.T. NuansaBening Cipta. 